Article

\title{
Analysis of Environmental References in the Texts of the Four Gospels Using Descriptive Statistics
}

\author{
Zoe Gareiou and Efthimios Zervas * \\ Laboratory of Technology and Policy of Energy and Environment, School of Science and Technology, \\ Hellenic Open University, 26335 Patra, Greece; zgareiou@gmail.com \\ * Correspondence: zervas@eap.gr; Tel.: +30-2610-367-566
}

Received: 12 July 2018; Accepted: 5 September 2018; Published: 7 September 2018

check for updates

\begin{abstract}
Christian ecotheology uses theology to examine the consequences of human action on ecology. It comes from the notion that the natural world is the creation and the good of God. The study of the Sacred Texts and the analysis of their references to the environment provides information on the relation of human beings to the environment and reveals the approach of each author. In this study, a detailed descriptive statistical analysis of the environmental references of the four Gospels of the New Testament was carried out. The different aspects of the environment (natural, anthropogenic, and spiritual) were explored and a quantitative analysis of the environmental references was performed for the texts of the four Gospels using descriptive statistics measures. The results show that the anthropogenic environment is the most commonly cited, with the spiritual environment coming next and the natural environment in the third position.
\end{abstract}

Keywords: ecotheology; environment; religion; New Testament

\section{Introduction}

In the view of the Christian world, God is an infinite spirit, personal, revealing himself to mankind through creation (His Works) and Christian belief of the revelation of His Son, Jesus Christ and the Scriptures (His Word) (Mcllgorm 2000). The Word of God is revealed to people through the Holy Bible (Old and New Testament). To the write the words of the Bible, the Divine factor cooperated with the human factor. The Divine factor, namely the Holy Spirit, assured infallibility in the Bible, while the human factor influenced the Bible through the styles and linguistic idioms according to the ability of the writers.

Ecotheology combines the terms ecology and theology. It is a religious concept that addresses ecological issues from a religious approach. It originated from the notion that the natural world is the creation and the good of God (Ezichi 2012). Ecotheology considers questions about the environment and humanity's relationship with the natural word (Dean-Drummond 2008). It is a particular expression of theology that emerged in the contemporary context of environmental awareness raised during the end of 20th century (Dean-Drummond 2008).

However, ecotheology has not emerged as an area of interest only during the last years. In the Old Church, the theology of creation was a part of faith and doctrine, although there was not a direct link to environmental degradation, but rather to God the Creator (Werner and Jeglitzka 2016). During the Reformation, reformers believed that human salvation did not exist without the salvation of the whole creation (Werner and Jeglitzka 2016). In the 18th and 19th centuries, Pietism emphasised individual salvation. A disconnection between science and technology emerged (Werner and Jeglitzka 2016). In the 20th century, ecotheology was rediscovered step by step, as early as 1925, by Leonard Ragaz in Zurich, then by Karl Barth in Basel (Werner and Jeglitzka 2016). 
A common assumption is that environmentalism began in the 1960s or the very early 1970s. The major scientific and social changes that took place during the $60 \mathrm{~s}$ and 70 s gave birth to the environmental movement; however, this movement also occurred thanks to the efforts of active pioneers several generations before (Pihkala 2016). According to Pihkala (2016), ecotheology, though a slowly rising movement, had notable proponents in the past. However, in the past, both the society and the church world were not mature enough for issues related to environmental consciousness; thus, changes occurred only gradually.

Pihkala (2016) reported four periods in early 20th-century ecotheology. The first corresponds to an increase in agrarian thought with ecotheological dimensions in North America. During the second period, socially active Christians started to include some environmental elements in their thought and action. The third period corresponds to the strong contribution of British theology on the value of "creation", wherein Anglicans made the first statements on ecotheology at the church level. During the last period, various theologians, standing between liberal and conservative theology, provided more reflection about ecotheology and served as bridge builders for later Christian environmentalism (Pihkala 2016).

As the early ecotheologians were part of the general movement of early environmentalism, they disseminated the ideas of other early environmentalists in their respective home contexts: theological schools, congregations, and church-level organizations (Pihkala 2016). At the same time, the societies around them were not as sensitive to environmental issues as they are nowadays (Pihkala 2016). However, early ecotheologians provided support to many people who were concerned about the situation of the environment and the general lack of nature-oriented elements in Christianity (Pihkala 2016).

The primary response made by Christians to the global environmental crisis was a call to develop a sense of spirituality with particular emphasis on the role of the environment (Schuenemann 2006). Ecotheology started noticeably in North America from the Faith-Man-Nature Group, convened by Philip Joranson in 1963, with support from the national Council of Churches (Schuenemann 2006). In 1967, Lynn White Jr. not only emphasised the direct connection between religion and ecology, but he placed the blame of the environmental crisis on the shoulders of Christianity (Schuenemann 2006). Further information on historical data about the rise and development of ecotheology can be found elsewhere (Pihkala 2016).

God created the Earth and then granted its management to humans. If humans succeed to manage the Earth well, then they will enjoy its provisions. However, if they become ecological despots and insist on exploiting the Earth, they will suffer great consequences, which could result in a climatic "hellfire", leading to a devastating and disastrous situation for humankind (Ezichi 2012). According to Ezichi (2012), Christian ecotheology uses theology to evaluate the consequences of human action on ecology and investigate how the moral principles of Christian theology could preserve nature. The core of this position is that nature was created by God and human beings are obliged to take care of the creation of the Glory of God (Ezichi 2012).

It should be noted that ecotheology is not a panacea. However, numerous studies have shown that in the USA, a country whose value systems are significantly influenced by biblical theological traditions, religious affiliations tend to promote positive environmental behaviors and attitudes rather than discourage them (Hitzhussen 2007). The growing interest in ecology has had the unexpected effect of granting new relevance to a theology interested not so much in the salvation of humans, but in the salvation of the whole creation-non-humans included (Latour 2009).

Therefore, for the study of ecological phenomena through the religion of Orthodox Christianity, it is necessary to study the first Holy Texts and to analyze their references to the environment. In our study, a detailed analysis of the environmental references of the Old and New Testament was carried out. The different aspects of the environment were determined and analyzed. As a first step, shown here, a quantitative analysis of the environmental references was performed in the texts of the four Gospels using descriptive statistics. Our aim was to statistically analyze the different environmental 
references as they were written in the four Gospels. This is the first paper of a greater work on the environmental analysis of the four Gospels. The next work will be focused on a cluster analysis of environmental references of the four Gospels (using Principal Component Analysis and other statistical methods). A more theoretical, textual, and grammatical analysis concerning environmental references will follow thereafter.

\section{Method}

This study examines the references to the environment and, in general, the relationship between humans and nature, as presented in the four Gospels of the New Testament. In particular, the four Gospels of the New Testament, namely the Gospel of Matthew, Gospel of Mark, Gospel of Luke, and Gospel of John, were studied. The commercially available edition by the Orthodox Christian Theologian Brotherhood, named "Zoe", of the four Gospels, translated to Modern Greek by J. Kolitsaras in 1975, was used for this work (Kolitsaras 1975).

The texts of the four Gospels were carefully analyzed and all words referring to the environment were identified. For the quantitative analysis of the environmental characteristics of the content of the texts, the environmental references were classified into three General Environmental Categories:

- Natural environment, with all references to nature,

- Anthropogenic environment, with all references to the anthropogenic world,

- Spiritual environment, with all references to the spiritual world.

The spiritual environment, although it contains spiritual references and refers principally to God, was included in the General Environmental Categories in order to be compared with the anthropogenic and natural environments.

Each General Environmental Category was then divided into the following Environmental Subcategories:

- Natural environment
1. Air
2. Soil
3. Water
4. Fauna
5. Flora

- Anthropogenic environment

1. Social environment

2. Economic environment

3. Cultural environment

- Spiritual environment
1. Divine
2. Ritual

Each word referring to the environment, depending on the feature it contains, was classified in the corresponding General Environmental Category and then in the Environmental Subcategories. The most common words used in the four Gospels can be found in Appendix A. For each word referring to the environment, the frequency of its occurrence was calculated in all four Gospels. The sum of words and their frequency of appearance in the General Environmental Categories and in the Environmental Subcategories were also counted. The total number of environmental reference words in each Gospel was determined in order to calculate the percentage of each word to the total number of words of each Category and Subcategory. 
Here, we have to note that the translation of a Gospel from one language to another can probably lead to a change of some words. For example, two words, having exactly the same meaning, are used in the Modern Greek translation for the word "stone": $\lambda i \theta$ oo and $\pi \varepsilon \varepsilon^{\prime} \rho \alpha$. For this reason, it is not certain than the application of the same methodology to the translation to another language will lead to the same numerical results. However, beyond these small numerical differences, we believe that the main trends will remain the same, independent of the language of the text.

\section{Results}

\subsection{Total References to Environemnt}

Table 1 shows the total number of words in each Gospel, the number of different words referring to the environment, the total environmental references per Gospel, and their percentage of the total number of words in each Gospel.

Table 1. Number of environmental references per Gospel.

\begin{tabular}{|c|c|c|c|c|c|}
\hline Gospels & $\begin{array}{c}\text { Total } \\
\text { Number } \\
\text { of Words }\end{array}$ & $\begin{array}{l}\text { Total Number of } \\
\text { Different Words } \\
\text { Referring to the } \\
\text { Environment* }\end{array}$ & $\begin{array}{c}\text { Total Number of } \\
\text { Environmental } \\
\text { References }\end{array}$ & $\begin{array}{c}\text { Percentage of } \\
\text { Environmental } \\
\text { References to the Total } \\
\text { Number of Words }(\%)\end{array}$ & $\begin{array}{c}\text { Ratio of } \\
\text { Environmental } \\
\text { References/Different } \\
\text { Words }\end{array}$ \\
\hline Matthew & 28,860 & 344 & 2338 & 8.10 & 6.80 \\
\hline Mark & 17,420 & 258 & 1376 & 7.90 & 5.33 \\
\hline Luke & 30,420 & 347 & 2400 & 7.89 & 6.92 \\
\hline
\end{tabular}

${ }^{*}$ It should be noted that the wealth of the Greek language offers a multitude of words and many different words can describe the same thing. For this, where several words have the same meaning, only one time is counted (e.g., two words are counted as one: $\lambda_{\imath}^{\prime} \theta 0 \sigma, \pi \varepsilon ́ \tau \rho \alpha=$ stone).

Specifically, the total number of words in each Gospel varies from 17,420 (Gospel of Mark) to 30,420 (Gospel of Luke), giving a ratio of almost 1:2. This is because each Gospel narrates different events and each Evangelist reports different scenes from the life and action of Jesus. The Gospel of John lacks the genealogy and refers more to Christ's action and teaching (Werner and Jeglitzka 2016). John wrote his Gospel after the other three Evangelists, completing them and quoting much that they had omitted (Kolitsaras 1975). Matthew's and Luke's texts are more explicit, as they provide us with the human ancestors of Jesus, while those of Mark and John provide only his divine ancestry. Quite the same variation is observed in the case of the total number of environmental references, from 1376 words in the case of the Gospel of Mark to 2400 words in the case of the Gospel of Luke. However, despite the above substantial differences among the four Gospels, the percentage of the environmental reference words is remarkably similar in all four Gospels-from 7.24\% in the case of the Gospel of John to $8.10 \%$ in the case of the Gospel of Matthew (mean value $=7.78 \%$, with relative standard deviation (standard deviation/average value, RSD) $=4.8 \%$ ).

For the total number of different words referencing the environment, the average number of all four Gospels is 286 different words, with a standard deviation (Stdev) of 73 words, or RSD of $25.5 \%$, indicating a quite significant scattering among the four Gospels. In the Gospels of Matthew and Luke, counting around 30,000 total words each, the numbers of different words referencing the environment are very similar: 344 and 347, respectively. We counted 25\% less relevant words (258) in the Gospel of Mark; however, with almost $40 \%$ less words in total, this Gospel is richer in unique environmental references than the other Gospels. In contrast to the Gospel of Mark, the Gospel of John has much fewer relevant words (196), almost the half that of the first two Gospels. With only about $20 \%$ less words in total, this Gospel is the poorest compared to the others in unique environmental references. The Gospel of John is more theological, since John's work reports more on the action of Jesus on the basis of his teaching. For this reason, a lower number of unique environmental references is expected in this text. 
It is remarkable that the ratio between the number of references and the number of unique words is quite similar in all four Gospels. This ratio varies from 5.33 in the case of Mark to 8.55 in the case of John, giving an average value of 6.90, a Stdev of 1.32, and an RSD of $19.07 \%$. This finding indicates that, despite the significant differences among the four Gospels, environmental references (as seen in total) exhibit great similarity.

\subsection{Results of the General Environmental Categories}

Table 2 shows, per Gospel, the percentage of references to the natural, anthropogenic, and spiritual environments to the total number of environmental references. From the total results of the three General Environmental Categories, it was observed that there is heterogeneity in the proportion of each General Environmental Category within the Gospel texts. The anthropogenic environment presented the highest number of relevant references, amounting to about half of the total environmental references, followed by the spiritual environment (about one-third of the total references) and the natural environment (about one-sixth to one-ninth of the total references).

Table 2. Environmental references of the General Environmental Categories.

\begin{tabular}{|c|c|c|c|c|c|c|c|c|c|}
\hline \multirow[t]{2}{*}{ Gospels } & \multicolumn{3}{|c|}{$\begin{array}{l}\text { Total Number of References to } \\
\text { the Environment }\end{array}$} & \multicolumn{3}{|c|}{$\begin{array}{l}\text { Percentage of References to the } \\
\text { Environment to the Total Number } \\
\text { of Words (\%) }\end{array}$} & \multicolumn{3}{|c|}{$\begin{array}{l}\text { Percentage of References to the } \\
\text { Environment to the Total Number } \\
\text { of Environmental References (\%) }\end{array}$} \\
\hline & Natural & Anthrop. & Spiritual & Natural & Anthrop. & Spiritual & Natural & Anthrop. & Spiritual \\
\hline Matthew & 367 & 1240 & 731 & 1.27 & 4.30 & 2.53 & 15.70 & 53.04 & 31.27 \\
\hline Mark & 189 & 761 & 426 & 1.08 & 4.37 & 2.45 & 13.74 & 55.31 & 30.96 \\
\hline Luke & 285 & 1306 & 809 & 0.94 & 4.29 & 2.66 & 11.88 & 54.42 & 33.71 \\
\hline John & 194 & 763 & 719 & 0.84 & 3.30 & 3.11 & 11.58 & 45.53 & 42.90 \\
\hline
\end{tabular}

The highest percentage of references to the natural environment is found in the Gospel of Matthew $(15.70 \%)$, while the Gospels of Luke and John have the lowest percentages for the natural environment $(11.88 \%$ and $11.58 \%$, respectively). For the anthropogenic environment, the higher percentage of references is found in the Gospel of Mark (55.31\%), while the Gospel of John has the lowest percentage of references to the anthropogenic environment (45.53\%). Contrary to the anthropogenic environment, the spiritual environment presents the opposite classification between the Gospel of Mark and the Gospel of John. The highest percentage of references related to the spiritual environment $(42.90 \%)$ is found in the Gospel of John, while the Gospel of Mark shows the lowest.

It should be noted that the fluctuations in total environmental references among the four Gospels are quite small. The natural environment accounts, on average in the four Gospels, for $13.23 \%$ of the total environmental references, with a Stdev of only 1.9 percentage points (or RSD $=14.4 \%$ ). The anthropogenic environment accounts for $52.08 \%$ on average, with a Stdev of 4.46 percentage points $(\mathrm{RSD}=8.57 \%$ ), and the spiritual environment accounts for $34.71 \%$, with a Stdev of 5.60 percentage points $(\mathrm{RSD}=16.12 \%)$. These results indicate that, as in the case of total environmental references, the environmental references of each category are treated in a quite homogeneous way by the four Gospels.

However, it should be noted that one Gospel, that of John, is an outlier in the last two categories, as it has, compared to the other three Gospels, about 10 percentage points less in the anthropogenic category and 10 points more in the spiritual one. Taking out this Gospel, the previous average percentages change to $54.25 \%$ in the case of the anthropogenic environment and $31.98 \%$ in the case of the spiritual environment. The value of the Stdev obtained by taking out the Gospel of John is very low-only 1.14 points (or RSD $=2.11 \%$ ) in the case of the anthropogenic environment and only 1.51 points (or $\mathrm{RSD}=4.71 \%$ ) in the case of the spiritual environment. These results indicate that the treatment of environmental references in the three Gospels are very homogeneous. Thus, it can be confirmed once more that the Gospel of John deals more with the spiritual than the anthropogenic items, as compared to the other three Gospels. The Gospel of John is characterized as more theological 
than the other three Gospels and, for this reason, the Christian Church called the Evangelist John as "John the Theologian" (Kolitsaras 1975). Our results are in support of this view.

Table 3 shows the results of the number of unique words referring to a General Environmental Category. As in the case of total environmental references, there is also a heterogeneity in the proportion of each General Environmental Category among the Gospels concerning the total number of different environmental reference words. The anthropogenic environment presents the highest number of relevant references, around $70 \%$ of the total, followed by the natural environment (about 20\%), while the spiritual environment comes last (about 8-12\%).

Table 3. Unique words referencing the environment, according to the General Environmental Categories.

\begin{tabular}{cccccccc}
\hline \multirow{2}{*}{ Gospels } & $\begin{array}{c}\text { Total Number of } \\
\text { Different Words } \\
\text { Referring to the } \\
\text { Environment }\end{array}$ & & \multicolumn{2}{c}{ Number of Different Words } & \multicolumn{3}{c}{$\begin{array}{c}\text { Percentage to the Total Number of } \\
\text { Different Words Referring to the } \\
\text { Environment (\%) }\end{array}$} \\
\cline { 3 - 8 } & & Natural & Anthrop. & Spiritual & Natural & Anthrop. & Spiritual \\
\hline Matthew & 344 & 70 & 247 & 27 & 20.35 & 71.80 & 7.85 \\
Mark & 258 & 53 & 178 & 27 & 20.54 & 68.99 & 10.47 \\
Luke & 347 & 69 & 251 & 27 & 19.88 & 72.33 & 7.78 \\
John & 196 & 36 & 135 & 25 & 18.37 & 68.88 & 12.76 \\
\hline
\end{tabular}

It should be noted that there is a change in the order of the percentage of the number of unique words compared to the respective percentage of the number of environmental references. In both cases, the anthropogenic environment occupies the first place with a great distance from the two following categories. However, in the case of the number of different words, the natural environment occupies the second place and the spiritual environment comes in third place. On the other hand, in the case of the number of environmental references, the order of these two categories is inversed, as they occupy the third and second places, respectively.

Similar to the total environmental references, fluctuations in the percentage of the different words in total environmental references are quite small. The natural environment accounts for $19.78 \%$ of the total environmental words in the four Gospels, on average, with a Stdev of only 0.98 percentage points (or RSD $=4.98 \%$ ). The anthropogenic environment accounts for $70.50 \%$ on average, with a Stdev of only 1.82 percentage points ( $R S D=2.59 \%$ ), and the spiritual environment accounts for $9.71 \%$, with a Stdev of 2.38 percentage points ( $\mathrm{RSD}=24.53 \%$ ). These results show once more that the four Gospels treat environmental words in a quite homogeneous way. It should be noted that the Gospel of John is not an outlier in the case of the number of different words, as it was in the case of environmental references.

Table 4 shows the ratio of environmental references/unique words according to the General Environmental Categories.

Table 4. Ratio of environmental references/unique words according to the General Environmental Categories.

\begin{tabular}{ccccc}
\hline \multirow{2}{*}{ Gospels } & \multicolumn{4}{c}{$\begin{array}{c}\text { Ratio of Environmental } \\
\text { References/Different Words }\end{array}$} \\
\cline { 2 - 5 } & All & Natural & Anthrop. & Spiritual \\
\hline Matthew & 6.80 & 5.24 & 5.02 & 27.07 \\
Mark & 5.33 & 3.57 & 4.28 & 15.78 \\
Luke & 6.92 & 4.13 & 5.20 & 29.96 \\
John & 8.55 & 5.39 & 5.65 & 28.76 \\
\hline
\end{tabular}

It is observed that this ratio remains quite close to the general one in the case of the natural and anthropogenic environments, but it deviates in the case of the spiritual environment. The first two categories have a ratio of about 4.5 to 5 , while the spiritual environment's ratio is 5 times higher, at about 25. More specifically, the ratio of environmental references/different words is, on average, 
4.58 in the case of the natural environment-from 3.57 in the case of Mark to 5.39 in the case of John, with a Stdev of 0.88 and an RSD of $19.20 \%$, which are quite similar to the values of the total ratios. This ratio is, on average, 5.02 in the case of the anthropogenic environment-from 4.28 in the case of Mark to 5.65 in the case of John, with a Stdev of 0.57 and an RSD of $11.38 \%$, which are quite smaller than the values of the total ratios. On the other hand, in the case of the spiritual environment, there is a significant difference from the other two categories. The ratio of the spiritual environment is more than 3 times higher than the total ratio; 25.39 on average (from 15.78 in the case of Mark to 29.96 in the case of Luke) and more disperse (the Stdev is 6.52 and the RSD is 25.67). This is because the Gospels are texts with a strong theological element, and therefore it is expected that the name of God will appear many times within these texts. According to Werner and Jeglitzka (2016), for Christians, the best available clue to God's identity and character may be found in the life and ministry of Jesus.

\subsection{Results of Environmental Subcategories}

This chapter presents the results of the Environmental Subcategories of the natural, anthropogenic, and spiritual environments.

\subsubsection{Natural Environment}

For each Gospel, the total references per subcategory (air, soil, water, fauna, and flora) of the natural environment and the percentage of references per subcategory to the total number of references to the natural environment are shown in Table 5. This table shows that there is an important heterogeneity among the environmental references for each Environmental Subcategory. The subcategory with the highest percentage is soil, with on average $30.76 \%$ of the total references, followed by air $(24.63 \%)$, flora $(18.38 \%)$, water $(15.75 \%)$, and fauna $(10.46 \%)$. It is quite unexpected that water (one of the main elements for life as well as a relative scarcity in the Middle East region) and fauna (which is one of the bases of human nutrition) occupy the last two places in the above ranking, while air is found in the second place.

Table 5. Number of references to the natural environment.

\begin{tabular}{ccccccc}
\hline \multirow{2}{*}{ Gospels } & $\begin{array}{c}\text { Total Number of } \\
\text { References to the } \\
\text { Natural Environment }\end{array}$ & \multicolumn{5}{c}{$\begin{array}{c}\text { Total References per Subcategory of the Natural Environment and } \\
\text { Corresponding Percentage to the Total Number of References to the } \\
\text { Natural Environment }\end{array}$} \\
\cline { 3 - 7 } & & Air & Soil & Water & Fauna & Flora \\
\hline Matthew & 367 & $98(26.70 \%)$ & $106(28.88 \%)$ & $46(12.53 \%)$ & $37(10.08 \%)$ & $80(21.80 \%)$ \\
Mark & 189 & $40(21.16 \%)$ & $61(32.28 \%)$ & $32(16.93 \%)$ & $17(8.99 \%)$ & $39(20.63 \%)$ \\
Luke & 285 & $71(24.91 \%)$ & $103(36.14 \%)$ & $28(9.82 \%)$ & $34(11.93 \%)$ & $49(17.19 \%)$ \\
John & 194 & $50(25.77 \%)$ & $50(25.77 \%)$ & $46(23.71 \%)$ & $21(10.82 \%)$ & $27(13.92 \%)$ \\
\hline
\end{tabular}

The ranking order of the five subcategories of the natural environment, as shown in Table 5, is followed by the texts of Matthew, Mark, and John, despite the fact that in the case of John's text the first two subcategories (soil and air) have exactly the same percentage. On the contrary, Luke's text does not follow the general classification of the five subcategories, as water is found in the last place while the fauna is in the second last place.

The five subcategories show significant differences of the dispersion values among the four Gospels. The Stdev is only 2.42 percentage points ( $\mathrm{RSD}=9.85 \%$ ) in the case of air, 1.23 percentage points ( $\mathrm{RSD}=11.81 \%$ ) in the case of fauna, and 4.45 percentage points (RSD $=14.49 \%$ ) in the case of soil, increasing to 3.56 percentage points $(\mathrm{RSD}=19.38 \%$ ) in the case of flora and 6.06 percentage points $(\mathrm{RSD}=38.48 \%$ ) in the case of water (the percentage of water varies from 9.82\% in the Gospel of Luke to $23.71 \%$ in the Gospel of John).

Table 6 shows the results of the number of unique words referring to an Environmental Subcategory of the natural environment. 
Table 6. Number of unique words referring to the natural environment.

\begin{tabular}{|c|c|c|c|c|c|c|}
\hline \multirow[t]{2}{*}{ Gospels } & \multirow{2}{*}{$\begin{array}{l}\text { Number of Different } \\
\text { Words Referring to the } \\
\text { Natural Environment }\end{array}$} & \multicolumn{5}{|c|}{$\begin{array}{c}\text { Number of Different Words per Subcategory of the Natural Environment } \\
\text { and Corresponding Percentage to the Total Number of Words of the } \\
\text { Natural Environment }\end{array}$} \\
\hline & & Air & Soil & Water & Fauna & Flora \\
\hline Matthew & 70 & $9(12.86 \%)$ & $16(22.86 \%)$ & 7 (10.00\%) & $19(27.14 \%)$ & 19 (27.14\%) \\
\hline Mark & 53 & 10 (18.87\%) & $13(24.53 \%)$ & $5(9.43 \%)$ & $9(16.98 \%)$ & $16(30.19 \%)$ \\
\hline Luke & 69 & $9(13.04 \%)$ & $18(26.09 \%)$ & $8(11.59 \%)$ & $17(24.64 \%)$ & $17(24.64 \%)$ \\
\hline John & 36 & $4(11.11 \%)$ & $9(25.00 \%)$ & $6(16.67 \%)$ & $6(16.67 \%)$ & $11(30.56 \%)$ \\
\hline
\end{tabular}

As in the case of the number of environmental references, Table 6 shows that the heterogeneity between the environmental words for each Environmental Subcategory is quite small. However, the ranking of the environmental words is not the same as the ranking of the environmental references. Here, the first subcategory is flora, with, on average $28.13 \%$ of the total words, followed by soil (24.62\%), fauna $(21.36 \%)$, air (13.97\%), and water $(11.92 \%)$.

As in the case of the number of environmental references, the five subcategories show significant differences in the dispersion values among the four Gospels concerning the number of environmental words. Moreover, for each one of the five subcategories, the dispersion among the four Gospels concerning the number of environmental references or the number of environmental words is not the same. The Stdev is only 1.34 percentage points ( $R S D=5.45 \%$ ) in the case of soil, 2.78 percentage points $(\mathrm{RSD}=9.90 \%$ ) in the case of flora, 3.29 percentage points $(\mathrm{RSD}=27.63 \%$ ) in the case of water, 3.38 percentage points ( $R S D=24.20 \%$ ) in the case of air, and reaches 5.33 percentage points $(\mathrm{RSD}=24.97 \%)$ in the case of fauna.

The ratio of environmental references/unique words of the five subcategories of the natural environment in the four Gospels is shown in Table 7.

Table 7. Ratio of environmental references/unique words of the natural environment.

\begin{tabular}{ccccccc}
\hline \multirow{2}{*}{ Gospels } & \multicolumn{5}{c}{ Ratio of Environmental References/Different Words } \\
\cline { 2 - 6 } & Natural & Air & Soil & Water & Fauna & Flora \\
\hline Matthew & 5.24 & 10.89 & 6.63 & 6.57 & 1.95 & 4.21 \\
Mark & 3.57 & 4.00 & 4.69 & 6.40 & 1.89 & 2.44 \\
Luke & 4.13 & 7.89 & 5.72 & 3.50 & 2.00 & 2.88 \\
John & 5.39 & 12.50 & 5.56 & 7.67 & 3.50 & 2.45 \\
\hline
\end{tabular}

Great differences are observed between the five subcategories on the ratio of environmental references/different words. The average value is 8.82 in the case of air, 6.03 in the case of water, 5.65 in the case of soil, 3.00 in the case of flora, and only 2.33 in the case of fauna. The disparities among the four Gospels are in general quite large; the corresponding RSDs of the Environmental Subcategories are $42.39 \%, 29.50 \%, 14.02 \%, 27.88 \%$, and $33.36 \%$, respectively. Furthermore, there is high heterogeneity among the four Gospels concerning the order of the ratio of environmental references/different words. It is remarkable that none of the Gospels follow the same order.

\subsubsection{Anthropogenic Environment}

For each Gospel, the total references per subcategory of the anthropogenic environment (social, economic, and cultural environments) and the percentage of references per subcategory to the total number of references to the anthropogenic environment are shown in Table 8. 
Table 8. Number of references to the anthropogenic environment.

\begin{tabular}{|c|c|c|c|c|}
\hline \multirow[t]{2}{*}{ Gospels } & \multirow{2}{*}{$\begin{array}{l}\text { Total Number of } \\
\text { References to the } \\
\text { Anthropogenic } \\
\text { Environment }\end{array}$} & \multicolumn{3}{|c|}{$\begin{array}{c}\text { Total References per Subcategory of the Anthropogenic } \\
\text { Environment and Percentage of References per } \\
\text { Subcategory to the Total Number of References to the } \\
\text { Anthropogenic Environment }\end{array}$} \\
\hline & & Social & Economic & Cultural \\
\hline Matthew & 1240 & $432(34.84 \%)$ & $786(63.39 \%)$ & $22(1.77 \%)$ \\
\hline Mark & 761 & $242(31.80 \%)$ & $491(64.52 \%)$ & $28(3.68 \%)$ \\
\hline Luke & 1306 & $434(33.23 \%)$ & $847(64.85 \%)$ & $25(1.91 \%)$ \\
\hline John & 763 & $260(34.08 \%)$ & $466(61.07 \%)$ & $37(4.85 \%)$ \\
\hline
\end{tabular}

High heterogeneity between the environmental references for each Environmental Subcategory is observed. The number of results related to the economic environment correspond to almost two-thirds of the total references. The references to the social environment correspond to about one-third of the total. The number of references to the cultural environment is very low, accounting for just $3-5 \%$ of the total references. It should be noted that this order of the three subcategories (economic, social, and cultural) is the same in all four Gospels, without any deviating from this classification. Also, the percentages of the first two subcategories among the four Gospels are identical, while for the cultural environment heterogeneity is observed.

More specifically, the percentage of the references to the economic environment to the total number of references to the anthropogenic environment is remarkably similar in all four Gospels-from $61.07 \%$ in the Gospel of John to $64.85 \%$ in the Gospel of Matthew (average $=63.45 \%$, Stdev $=1.7$, RSD $=2.69 \%$ ). The percentage of the references to the social environment to the total number of references to the anthropogenic environment is also very similar in all four Gospels-from 31.80\% in the Gospel of Mark to $34.84 \%$ in the Gospel of Matthew (average $=33.48 \%$, Stdev $=1.3$, RSD $=3.88 \%$ ). However, the percentage of the references to the cultural environment to the total number of references to the anthropogenic environment shows significant heterogeneity-from $1.77 \%$ in the Gospel of Matthew to $4.85 \%$ in the Gospel of John, giving a ratio of almost 1:3 (average $=3.05 \%$, Stdev $=1.48$, RSD $=48.38 \%$ ). Once more, the Gospel of John is found to be an outlier and our results show that this Gospel is not only more spiritual compared to the other three Gospels, but also more cultural.

Table 9 shows the results of the number of unique words of the subcategories of the anthropogenic environment.

Table 9. Number of unique words referring to the anthropogenic environment.

\begin{tabular}{|c|c|c|c|c|}
\hline \multirow[t]{2}{*}{ Gospels } & \multirow[t]{2}{*}{$\begin{array}{l}\text { Number of Different Words } \\
\text { Referring to the } \\
\text { Anthropogenic Environment }\end{array}$} & \multicolumn{3}{|c|}{$\begin{array}{l}\text { Number of Different Words per Subcategory of the } \\
\text { Anthropogenic Environment and Corresponding } \\
\text { Percentage to the Total Number of Words of the } \\
\text { Anthropogenic Environment }\end{array}$} \\
\hline & & Social & Economic & Cultural \\
\hline Matthew & 247 & 69 (27.94\%) & $167(67.61 \%)$ & $11(4.45 \%)$ \\
\hline Mark & 178 & $46(25.84 \%)$ & $122(68.54 \%)$ & $10(5.62 \%)$ \\
\hline Luke & 251 & $54(21.51 \%)$ & $185(73.71 \%)$ & $12(4.78 \%)$ \\
\hline John & 135 & $33(24.44 \%)$ & $92(68.15 \%)$ & $10(7.41 \%)$ \\
\hline
\end{tabular}

The percentage of the words of the economic, social, and cultural environments are very close to the percentages of the references of these subcategories. Specifically, $69.50 \%$ of the words of the anthropogenic environment are found in the subcategory of the economic environment, $24.93 \%$ in the social environment, and $5.56 \%$ in the cultural environment.

In contrast to the natural environment, the three subcategories of the anthropogenic environment follow the same order in the case of the number of different words, as in the case of percentage of references per subcategory to the total number of references to the anthropogenic environment. 
As in the case of the total references, the number of words is quite similar in each of the four Gospels. The Stdev of the economic environment is only 2.83 percentage points (RSD $=4.07 \%$ ) and that of the social environment only 2.69 percentage points ( $R S D=10.81 \%$ ). However, as seen previously, the percentage of words referencing the cultural environment to the total number of words referencing the anthropogenic environment shows significant heterogeneity-from $4.45 \%$ in the Gospel of Matthew to $7.41 \%$ in the Gospel of John (average $=5.57 \%$, Stdev $=1.32, \mathrm{RSD}=23.81 \%$ ). Once more, the Gospel of John verifies its higher cultural devotion compared to the other three Gospels.

The ratio of environmental references/unique words is shown in Table 10. As in the case of the subcategories of the natural environment, great differences are observed between the three subcategories of the anthropogenic environment. Specifically, the average value is 6.86 in the social, 4.59 in the economic, and only 2.65 in the cultural environments. The disparities among the four Gospels are in general quite large (except in the case of the economic environment); the corresponding RSDs are $19.45 \%, 9.40 \%$, and $29.83 \%$.

Table 10. Ratio of environmental references/unique words of the anthropogenic environment.

\begin{tabular}{ccccc}
\hline \multirow{2}{*}{ Gospels } & \multicolumn{3}{c}{ Ratio of Environmental References/Different Words } \\
\cline { 2 - 5 } & Anthropogenic & Social & Economic & Cultural \\
\hline Matthew & 5.02 & 6.26 & 4.71 & 2.00 \\
Mark & 4.28 & 5.26 & 4.02 & 2.80 \\
Luke & 5.20 & 8.04 & 4.58 & 2.08 \\
John & 5.65 & 7.88 & 5.07 & 3.70 \\
\hline
\end{tabular}

Also, it should be noted that the social environment occupies the first place, while the economic environment comes in second. This is due to the high number of different words related to the economic environment, while the social environment presents a smaller number of different words.

\subsubsection{Spiritual Environment}

For each Gospel, the total references per subcategory of the spiritual environment (divine and ritual) and the percentage of references per subcategory to the total number of references to the spiritual environment are shown in Table 11.

Table 11. Number of references to the spiritual environment.

\begin{tabular}{cccc}
\hline Gospels & $\begin{array}{c}\text { Total Number of } \\
\text { References to the } \\
\text { Spiritual Environment }\end{array}$ & $\begin{array}{c}\text { Total References per Subcategory of the Spiritual } \\
\text { Environment and Percentage of References per } \\
\text { Subcategory to the Total Number of References to } \\
\text { the Spiritual Environment }\end{array}$ \\
\cline { 3 - 4 } & 731 & Divine & Ritual \\
\hline Matthew & 426 & $544(74.42 \%)$ & $187(25.58 \%)$ \\
Mark & 809 & $618(74.65 \%)$ & $108(25.35 \%)$ \\
Luke & 719 & $640(79.11 \%)$ & $169(20.89 \%)$ \\
John & $633(88.04 \%)$ & $86(11.96 \%)$ \\
\hline
\end{tabular}

The percentage of the references to the divine environment corresponds to about four-fifths $(79.05 \%)$ of the total, while the percentage of the ritual environment makes up the remaining one-fifth (20.94\%). The four Gospels have quite similar percentages. This can be justified because the four Gospels are fundamental theological texts and, therefore, are expected to contain frequent references to God and Divine beings and events. Moreover, there is extensive reference to rituals but, as expected due to their fundamental scope, this part is much lower than references to the Divine.

The Stdev is 6.36 percentage points in the case of the divine environment (RSD $=8.05 \%$ ) and 6.36 percentage points in the case of the ritual environment $(\mathrm{RSD}=30.40 \%)$. However, the Gospel of John is found once more to be an outlier, as the percentage of the divine environment is quite higher and 
the percentage of the ritual environment is quite lower (both 9-14 percentage points) than the other three Gospels. Taking out the Gospel of John, the variability of the other three Gospels is even lower. The average value of the divine environment is $76.05 \%$, with a Stdev of only 2.64 percentage points (giving an RSD of 3.47\%) and the average value of the ritual environment is $23.94 \%$, with a Stdev of only 2.64 percentage points (giving an RSD of $11.05 \%$ ). Once more, the Gospel of John confirmed its higher spiritual content compared to the other three Gospels.

Table 12 shows the results of the number of unique words referring to a General Environmental Category. In contrast to the percentage of the references to the divine environment, the divine environment is found in second place in the ranking concerning the number of different words, while the ritual environment takes first place. There is a small number of different words for the divine with several references each, while there is a large number of different words referring the ritual environment, albeit with lower occurrence.

Table 12. Number of unique words referring to the spiritual environment.

\begin{tabular}{cccc}
\hline \multirow{2}{*}{ Gospels } & $\begin{array}{c}\text { Number of Different } \\
\text { Words Referring to the } \\
\text { Spiritual Environment }\end{array}$ & $\begin{array}{c}\text { Number of Different Words per Subcategory of the } \\
\text { Spiritual Environment and Corresponding } \\
\text { Percentage to the Total Number of Words of the } \\
\text { Spiritual Environment }\end{array}$ \\
\cline { 3 - 4 } & 27 & Divine & Ritual \\
\hline Matthew & 27 & $9(33.33 \%)$ & $18(66.67 \%)$ \\
Mark & 27 & $10(37.04 \%)$ & $17(62.96 \%)$ \\
Luke & 25 & $10(37.04 \%)$ & $17(62.96 \%)$ \\
John & $9(36.00 \%)$ & $16(64.00 \%)$ \\
\hline
\end{tabular}

The number of unique words is similar in all four Gospels: 25-27. About the one-third of them (35.85\% on average, $9-10$ words) refer to the divine environment and the remaining two-thirds $(64.14 \%$, 16-18 words) refer to the ritual one. The four Gospels have quite similar percentages of the two subcategories. The Stdev is 1.74 percentage points in the case of the divine environment ( $R S D=4.88 \%$ ) and 1.74 percentage points in the case of the ritual one ( $\mathrm{RSD}=2.72 \%)$. The Gospel of John is not an outlier in this case.

Table 13 shows the ratio of environmental references/unique words of the spiritual environment.

Table 13. Ratio of environmental references/unique words of the spiritual environment.

\begin{tabular}{cccc}
\hline \multirow{2}{*}{ Gospels } & \multicolumn{2}{c}{ Ratio of Environmental References/Different Words } \\
\cline { 2 - 4 } & Spiritual & Divine & Ritual \\
\hline Matthew & 27.07 & 60.44 & 10.39 \\
Mark & 15.78 & 31.80 & 6.35 \\
Luke & 29.96 & 64.00 & 9.94 \\
John & 28.76 & 70.33 & 5.38 \\
\hline
\end{tabular}

This ratio is extremely high in the case of the divine environment, 56.64 on average. This is not surprising giving the theological scope of the four Gospels. However, great differences are also observed among the four Gospels-the ratio varies from 31.80 in the Gospel of Mark to 70.33 in the Gospel of John, giving a Stdev of 17.06 and an RSD of 30.12\%. The ratio of the ritual environment is much lower, only 8.01 on average, but the differences among the four Gospels were significant-the ratio varied from 5.38 in the case of John to 10.39 in the case of Matthew, giving a Stdev of 2.52 and an RSD of $31.46 \%$. This is because, as mentioned above, the Gospel of John is more theological than the other three Gospels and more references are made by John to theological events and to God in general.

\section{Conclusions}

In this study, a quantitative analysis of environmental references in the texts of the four Gospels was performed using descriptive statistics. In particular, the environment was divided into the 
categories of natural, anthropogenic, and spiritual environments, and the relevant environmental references were counted.

The results show that there is relative homogeneity in the Gospels and, in general, the anthropogenic environment is cited most often, with the spiritual environment following, while the natural environment is found in the third position. However, the Gospel of John shows several differences from the other Gospels, because it strongly underlines the spiritual and cultural elements in the whole text.

In addition, the texts under study are theological texts, where the authors' discourse often follows parallels, symbolism, and allegories. They are diachronic texts, in that they are still observed and followed to date by a large number of people all over the world, and as they are textbooks for the faithful of Orthodox Christianity. Therefore, from the analysis of the texts of the Gospels and the results, we can gain important information about the way of life of the people of the time, but also about the general long-term relationship between humans and the environment (that is, the natural world), as seen from a theological point of view.

It is concluded that the human factor plays an important role, as humans are a sovereign member of society and an integral part of nature. Human exploits the environment for their survival and growth, as well as for the production of valuable goods, while managing the land and enjoying its provisions. At the same time, humans develop the spiritual environment. In the living environment, humans constantly seeks God. They search for Divine beings and events and follow sacred rituals. However, they do not stop observing nature and natural events, such as the sky, the Earth, and everything that comes from nature and the natural environment. That is, all three General Environmental Categories coexist in nature and interact with each other; the anthropogenic, the natural, and the spiritual environments are consistent with each other and contribute to the relationship between humans and nature.

Author Contributions: E.Z. contributed to "conceptualization; methodology; validation; writing—original draft preparation; writing - review and editing; supervision", while Z.G. contributed to "methodology; validation; investigation; data curation; writing—original draft preparation."

Funding: This research received no external funding.

Conflicts of Interest: The authors declare no conflict of interest.

\section{Appendix A}

Table A1. List of Most Common Words.

\begin{tabular}{|c|c|c|c|c|c|c|c|}
\hline \multicolumn{8}{|c|}{ Natural Environment } \\
\hline \multirow{2}{*}{ Subcategory } & \multirow{2}{*}{ Word in Greek } & \multirow{2}{*}{ Word } & \multicolumn{4}{|c|}{ Number of References per Gospel } & \multirow{2}{*}{$\begin{array}{c}\text { Total Number o } \\
\text { References }\end{array}$} \\
\hline & & & Matthew & Mark & Luke & John & \\
\hline \multirow{3}{*}{ air } & 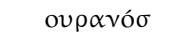 & heaven & 68 & 18 & 50 & 41 & 177 \\
\hline & $\dot{\eta} \lambda \operatorname{lo\sigma }^{\prime}$ & sun & 5 & 8 & 8 & 6 & 27 \\
\hline & $\alpha{ }^{\prime} \varepsilon \mu o \sigma$ & wind & 10 & 5 & 5 & 2 & 22 \\
\hline \multirow{4}{*}{ soil } & $\gamma \eta$ & earth & 40 & 17 & 30 & 20 & 107 \\
\hline & $\lambda i \theta o \sigma$ & stone & 18 & 9 & 16 & 8 & 51 \\
\hline & óроб & mountain & 12 & 10 & 16 & 6 & 44 \\
\hline & $\varepsilon ́ \rho \eta \mu о \sigma$ & desert & 9 & 12 & 11 & 7 & 39 \\
\hline \multirow{3}{*}{ water } & $\theta \dot{\alpha} \lambda \alpha \sigma \sigma \alpha$ & sea & 21 & 20 & 8 & 11 & 60 \\
\hline & 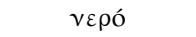 & water & 10 & 6 & 6 & 24 & 46 \\
\hline & $\pi \mathrm{o} \tau \dot{\alpha} \mu \iota$ & river & 6 & 4 & 4 & 5 & 19 \\
\hline \multirow{2}{*}{ fauna } & $\psi \alpha ́ \rho \iota$ & fish & 8 & 6 & 9 & 12 & 35 \\
\hline & $\pi \varepsilon \rho \iota \sigma \tau \varepsilon \dot{\varepsilon} \rho \iota$ & dove & 3 & 2 & 2 & 3 & 10 \\
\hline \multirow{4}{*}{ flora } & к $\alpha \rho \pi \delta ́ \sigma$ & fruit & 18 & 7 & 13 & 10 & 48 \\
\hline & $\delta \varepsilon ́ v \tau \rho O$ & tree & 11 & 2 & 7 & 0 & 20 \\
\hline & $\sigma \pi \hat{\rho} \rho \circ \sigma$ & seed & 11 & 5 & 4 & 0 & 20 \\
\hline & $\mu \cup ́ \rho o$ & myrrh & 4 & 4 & 4 & 5 & 17 \\
\hline
\end{tabular}


Table A1. Cont.

\begin{tabular}{|c|c|c|c|c|c|c|c|}
\hline \multicolumn{8}{|c|}{ Anthropogenic Environment } \\
\hline \multirow{2}{*}{ Subcategory } & \multirow{2}{*}{ Word in Greek } & \multirow{2}{*}{ Word } & \multicolumn{4}{|c|}{ Number of References per Gospel } & \multirow{2}{*}{$\begin{array}{c}\text { Total Number o } \\
\text { References }\end{array}$} \\
\hline & & & Matthew & Mark & Luke & John & \\
\hline \multirow{14}{*}{ social } & $\delta \iota \delta \alpha \sigma \kappa \alpha \lambda i \alpha$ & teaching & 30 & 29 & 44 & 51 & 154 \\
\hline & $\delta \iota \delta \alpha ́ \sigma \kappa \alpha \lambda \circ \sigma$ & teacher & 28 & 25 & 34 & 25 & 112 \\
\hline & $\Phi \alpha \rho \iota \sigma \alpha i ́ o \iota$ & Pharisees & 33 & 16 & 35 & 21 & 105 \\
\hline & $\beta \alpha \sigma \iota \lambda \varepsilon^{\prime} \alpha$ & reign & 25 & 18 & 52 & 7 & 102 \\
\hline & $\beta \alpha \sigma \iota \lambda \iota \alpha ́ \sigma$ & king & 28 & 14 & 20 & 20 & 82 \\
\hline & $\theta \varepsilon \rho \alpha \pi \varepsilon^{\prime} \alpha$ & treatment & 26 & 9 & 33 & 9 & 77 \\
\hline & $\gamma \rho \alpha \mu \mu \alpha \tau \varepsilon i \sigma \sigma$ & secretaries & 23 & 24 & 17 & 2 & 66 \\
\hline & vó ${ }^{\circ}$ & low & 12 & 5 & 24 & 17 & 58 \\
\hline & $\kappa \alpha \tau \alpha \delta i ́ k \eta$ & conviction & 14 & 6 & 9 & 13 & 42 \\
\hline & $\tau \cup \varphi \lambda{ }^{\prime} \sigma$ & blind & 12 & 5 & 7 & 18 & 42 \\
\hline & $\gamma \alpha \dot{\mu} \mu \sigma$ & marriage & 15 & 5 & 14 & 3 & 37 \\
\hline & $v \gamma \iota \dot{\prime} \sigma$ & healthy & 7 & 7 & 8 & 7 & 29 \\
\hline & $\varphi \tau \omega \chi o ́ \sigma$ & poor & 4 & 5 & 12 & 4 & 25 \\
\hline & $\pi \lambda$ oú $\sigma \iota \sigma$ & rich & 4 & 4 & 14 & 0 & 22 \\
\hline \multirow{26}{*}{ economic } & $\pi \hat{\prime} \lambda \eta$ & city & 77 & 51 & 117 & 55 & 300 \\
\hline & $\sigma \pi i \tau \iota$ & house & 33 & 33 & 58 & 13 & 137 \\
\hline & 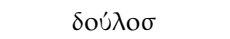 & slave & 43 & 9 & 41 & 17 & 110 \\
\hline & $\pi \varepsilon \rho \operatorname{co\chi ń}$ & area & 27 & 21 & 26 & 21 & 95 \\
\hline & 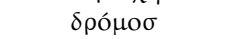 & road & 28 & 20 & 28 & 6 & 82 \\
\hline & $\varepsilon \vee \delta u ́ \mu \alpha \tau \alpha$ & clothes & 29 & 17 & 23 & 11 & 80 \\
\hline & $v \alpha o ́ \sigma$ & church & 26 & 11 & 21 & 15 & 73 \\
\hline & $\pi \lambda$ oío & ship & 14 & 19 & 11 & 13 & 57 \\
\hline & 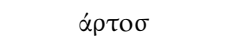 & breadstuff & 14 & 6 & 16 & 19 & 55 \\
\hline & $\pi \rho o ́ \beta \alpha \tau о$ & sheep & 15 & 2 & 5 & 31 & 53 \\
\hline & $\psi \omega \mu i ́$ & bread & 8 & 20 & 9 & 12 & 49 \\
\hline & $v \pi \eta \rho \varepsilon ́ \tau \eta \sigma$ & servant & 10 & 7 & 17 & 15 & 49 \\
\hline & xwoı́ & village & 8 & 13 & 15 & 9 & 45 \\
\hline & $\mu \vee \eta \mu \varepsilon i ́ o$ & tomb & 8 & 7 & 12 & 15 & 42 \\
\hline & $\tau \rho \alpha \pi \varepsilon \varepsilon_{l}$ & table & 5 & 4 & 17 & 6 & 32 \\
\hline & oíkoo & village & 12 & 7 & 7 & 5 & 31 \\
\hline & $\alpha \mu \pi \varepsilon \lambda_{\iota}$ & vineyard & 12 & 7 & 8 & 2 & 29 \\
\hline & $\sigma \tau \rho \alpha \tau \iota \omega ́ \tau \eta \sigma$ & soldier & 7 & 2 & 7 & 13 & 29 \\
\hline & $\chi \rho \eta^{\prime} \mu \alpha \tau \alpha$ & money & 5 & 5 & 15 & 2 & 27 \\
\hline & $\theta \varepsilon \rho \iota \sigma \mu o ́ \sigma$ & harvest & 10 & 2 & 4 & 10 & 26 \\
\hline & $\theta u ́ \rho \alpha$ & door & 8 & 5 & 5 & 8 & 26 \\
\hline & $\sigma \pi \mathrm{o} \rho \dot{\alpha}$ & sowing & 5 & 10 & 6 & 4 & 25 \\
\hline & 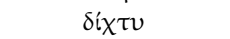 & net & 5 & 3 & 9 & 7 & 24 \\
\hline & $\chi \omega \rho \alpha ́ \varphi \iota$ & field & 7 & 5 & 11 & 0 & 23 \\
\hline & $\pi \mathrm{\pi} \mu \varepsilon \varepsilon \alpha \sigma$ & shepherd & 5 & 2 & 3 & 13 & 23 \\
\hline & $\gamma \varepsilon \omega \rho \gamma \delta ́ \sigma$ & farmer & 7 & 8 & 6 & 0 & 21 \\
\hline \multirow{4}{*}{ cultural } & $\varepsilon о \rho \tau \eta^{\prime} \tau o v ~ \Pi \alpha ́ \alpha \chi \alpha$ & $\begin{array}{c}\text { Easter } \\
\text { celebration }\end{array}$ & 9 & 7 & 11 & 0 & 27 \\
\hline & $\varepsilon 0 \rho \tau \dot{n}^{\prime}$ & feast & 0 & 1 & 1 & 15 & 17 \\
\hline & 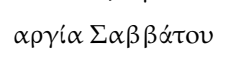 & $\begin{array}{l}\text { Saturday } \\
\text { holiday }\end{array}$ & 1 & 2 & 2 & 3 & 8 \\
\hline & $\pi \alpha \rho \alpha ́ \delta$ oo & tradition & 0 & 7 & 0 & 1 & 8 \\
\hline \multicolumn{8}{|c|}{ Spiritual Environment } \\
\hline \multirow{2}{*}{ Subcategory } & \multirow{2}{*}{ Word in Greek } & \multirow{2}{*}{ Word } & \multicolumn{4}{|c|}{ Number of References per Gospel } & Total Number of \\
\hline & & & Matthew & Mark & Luke & John & References \\
\hline \multirow{8}{*}{ divine } & $\theta \varepsilon \delta ́ \tau \eta \tau \alpha$ & deity & 358 & 230 & 451 & 494 & 1533 \\
\hline & $\pi \rho о \varphi \dot{r} \tau \eta \sigma$ & prophet & 41 & 17 & 48 & 18 & 124 \\
\hline & $\theta \alpha u ́ \mu \alpha$ & miracle & 23 & 17 & 19 & 44 & 103 \\
\hline & $\alpha v \alpha ́ \sigma \tau \alpha \sigma \eta$ & resurrection & 23 & 16 & 27 & 32 & 98 \\
\hline & $\begin{array}{l}\alpha \kappa \alpha ́ \theta \alpha \rho \tau \alpha \\
\pi v \varepsilon \dot{v} \mu \alpha \tau \alpha\end{array}$ & unclean spirits & 25 & 19 & 39 & 15 & 98 \\
\hline & $\begin{array}{l}\alpha \gamma \gamma \varepsilon \lambda \iota \kappa \alpha ́ \\
\pi v \varepsilon \dot{u} \mu \alpha \tau \alpha\end{array}$ & angelic spirits & 23 & 6 & 34 & 5 & 68 \\
\hline & 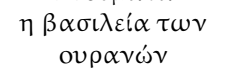 & $\begin{array}{l}\text { the kingdom } \\
\text { of heaven }\end{array}$ & 43 & 3 & 9 & 0 & 55 \\
\hline & $\pi \rho \circ \varphi \eta \tau \varepsilon i \alpha$ & prophecy & 7 & 7 & 8 & 18 & 40 \\
\hline
\end{tabular}


Table A1. Cont.

\begin{tabular}{|c|c|c|c|c|c|c|c|}
\hline \multicolumn{8}{|c|}{ Spiritual Environment } \\
\hline \multirow{2}{*}{ Subcategory } & \multirow{2}{*}{ Word in Greek } & \multirow{2}{*}{ Word } & \multicolumn{4}{|c|}{ Number of References per Gospel } & \multirow{2}{*}{$\begin{array}{c}\text { Total Number of } \\
\text { References }\end{array}$} \\
\hline & & & Matthew & Mark & Luke & John & \\
\hline \multirow{10}{*}{ ritual } & $\alpha \rho \chi\left\llcorner\varepsilon \rho \varepsilon \varepsilon^{\prime} \alpha \sigma\right.$ & high priest & 24 & 21 & 19 & 26 & 90 \\
\hline & $\beta \alpha ́ \pi \tau \iota \sigma \mu \alpha$ & baptism & 28 & 16 & 22 & 19 & 85 \\
\hline & $\kappa \eta ́ \rho v \gamma \mu \alpha$ & preaching & 23 & 16 & 27 & 9 & 75 \\
\hline & $\pi \rho \circ \sigma \varepsilon v \times \dot{n}$ & prayer & 19 & 13 & 29 & 1 & 62 \\
\hline & $\sigma u v \alpha \gamma \omega \gamma \dot{\eta}$ & synagogue & 10 & 10 & 16 & 5 & 41 \\
\hline & $\pi \rho \circ \sigma \kappa u ́ v \eta \mu \alpha$ & pilgrimage & 11 & 2 & 7 & 8 & 28 \\
\hline & о́ркоб & vow & 22 & 4 & 0 & 0 & 26 \\
\hline & $\vee \eta \sigma \tau \varepsilon i \alpha$ & fasting & 10 & 7 & 5 & 0 & 22 \\
\hline & 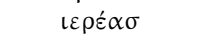 & priest & 5 & 3 & 9 & 1 & 18 \\
\hline & $\begin{array}{c}\pi \rho о \sigma \varphi о \rho \alpha ́ \\
\theta v \sigma i \alpha \sigma\end{array}$ & $\begin{array}{l}\text { offering of } \\
\text { sacrifice }\end{array}$ & 6 & 3 & 7 & 2 & 18 \\
\hline
\end{tabular}

\section{References}

Dean-Drummond, Celia. 2008. Trends in ecology and environment. In Eco-Theology. Winona: Saint Mary's Press, pp. 11-16, ISBN 978-1-59982-013-2.

Ezichi, Ituma. 2012. Christocentric Ecotheology and Climate Change. Open Journal of Philosophy 3: 126-30. [CrossRef]

Hitzhussen, Gregory. 2007. Judeo-Christian theology and the environment: moving beyond scepticism to new sources for environmental education in the United States. Environmental Education Research 13: 55-74. [CrossRef]

Kolitsaras, John. 1975. The New Testament. Athens: Theologian Brothers "Zoe", pp. 401-8.

Latour, Bruno. 2009. Will non-humans be saved? An argument in ecotheology. Journal of the Royal Anthropological Institute (N.S.) 15: 459-75. [CrossRef]

Mcllgorm, Alistair. 2000. Towards an Eco-Theology of Fisheries Management? Paper presented at Tenth Biennial Conference of the International Institute of Fisheries Economics and Trade (Microbehavior and Macroresults), Corvallis, OR, USA, July 10-14.

Pihkala, Panu. 2016. Rediscovery of Early Twentieth-Century Ecotheology. Open Theology 2: 68-85. [CrossRef] Schuenemann, Tyler. 2006. Ecological Aspects of Religion: Christianity and Daoism. UW-L Journal of Undergraduate Research IX 8: 1.

Werner, Dietrich, and Elizabeth Jeglitzka. 2016. Eco-Theology, Climate Justice and Food Security-Theological Education and Christian Leadership Development. Geneva: Globethics.net, pp. 311-18, ISBN 978-2-88931-144-6.

(C) 2018 by the authors. Licensee MDPI, Basel, Switzerland. This article is an open access article distributed under the terms and conditions of the Creative Commons Attribution (CC BY) license (http:/ / creativecommons.org/licenses/by/4.0/). 